\title{
Impact of Renin-Angiotensin-Aldosterone System Inhibition on Mortality in Critically III COVID-19 Patients with Pre-Existing Hypertension: A Prospective Cohort Study
}

Kei Sato ( $\sim$ m02045ks@gmail.com )

The Prince Charles Hospital

Nicole White

Queensland University of Technology (QUT)

Jonathon P. Fanning

The Prince Charles Hospital

Nchafatso Obonyo

The Prince Charles Hospital

Michael H. Yamashita

University of Manitoba

Vinesh Appadurai

The Prince Charles Hospital

Anna Ciullo

University of Utah Health

Meryta May

Sullivan Nicolaides Pathology

Elliott T. Worku

The Prince Charles Hospital

Leticia Helms

The Prince Charles Hospital

Shinichiro Ohshimo

Hiroshima University

Dafsah A. Juzar

National Cardiovascular Center Harapan Kita Jacky Y. Suen

The Prince Charles Hospital

Gianluigi Li Bassi

The Prince Charles Hospital

John F. Fraser

The Prince Charles Hospital 


\section{Rakesh C. Arora}

University of Manitoba

\section{COVID-19 Critical Care Consortium}

The Prince Charles Hospital

\section{Research Article}

Keywords: angiotensin-converting enzyme inhibitors, angiotensin receptor blockers, severe acute respiratory syndrome coronavirus 2, COVID-19, critical care

Posted Date: October 12th, 2021

DOl: https://doi.org/10.21203/rs.3.rs-898264/v1

License: (c) (i) This work is licensed under a Creative Commons Attribution 4.0 International License. Read Full License

Version of Record: A version of this preprint was published at BMC Cardiovascular Disorders on March 23rd, 2022. See the published version at https://doi.org/10.1186/s12872-022-02565-1. 


\section{Abstract}

\section{Background}

The influence of renin-angiotensin-aldosterone system (RAAS) inhibitors on the critically ill COVID-19 patients with pre-existing hypertension remains uncertain. This study examined the impact of previous use of angiotensin-converting enzyme inhibitors (ACEi) and angiotensin receptor blockers (ARB) on the critically ill COVID-19 patients.

\section{Methods}

Data from an international, prospective, observational cohort study involving 354 hospitals spanning 54 countries were included. A cohort of 746 COVID-19 patients with pre-existing hypertension admitted to intensive care units (ICUs) in 2020 were targeted. Multi-state survival analysis was performed to evaluate in-hospital mortality and hospital length of stay up to 90 days following ICU admission.

\section{Results}

A total of 746 patients were included - 543 (73\%) with pre-existing hypertension had received ACEi/ARBs before ICU admission, while $203(27 \%)$ had not. Cox proportional hazards model showed that previous ACEi/ARB use was associated with a decreased hazard of in-hospital death ( $\mathrm{HR}, 0.73,95 \% \mathrm{Cl}, 0.58$ to 0.93). Sensitivity analysis adjusted for propensity scores showed similar results for hazards of death. The average length of hospital stay was longer in ACEi/ARB group with 21.4 days (95\% Cl: 19.9 to 23.0 days) in ICU and 6.7 days (5.9 to 7.6 days) in general ward compared to non-ACEi/ARB group with 16.2 days (14.1 to 18.5 days) and 6.3 days (5.0 to 7.7 days), respectively. When analysed separately, there was insufficient evidence of differential effects between ACEi and ARB use on the hazards of death and discharge.

\section{Conclusions}

In critically ill COVID-19 patients with comorbid hypertension, use of ACEi/ARBs prior to ICU admission was associated with a reduced risk of in-hospital mortality following adjustment for baseline characteristics although patients with ACEi/ARB showed longer length of hospital stay.

\section{Background}

The effect of renin-angiotensin-aldosterone system (RAAS) therapy on an individual's susceptibility to, and severity of, COVID-19 has been a source of debate throughout the COVID-19 pandemic(1-3). The biological rationale for this arises from the understanding that severe acute respiratory syndrome coronavirus-2 (SARS-CoV-2), the viral agent responsible for COVID-19, enters human target cells by binding to the membrane-bound mono-carboxypeptidase - angiotensin-converting enzyme 2 (ACE-2) resulting in both internalization and degradation of the enzyme(4-6). ACE-2 expression is especially high in respiratory epithelium(7) - the main route of SARS-CoV-2 entry into the body. 
Mechanistically, treatment with RAAS inhibitors - like angiotensin-converting enzyme inhibitors (ACEi) and angiotensin receptor blockers (ARBs) - is known to induce the upregulation of ACE-2 expression, and it is around this that speculation hinges and has resulted in conflicting hypotheses $(1-3,8,9)$. On one hand, RAAS inhibitors could promote more severe COVID-19, with upregulated ACE-2 increasing the substrate for SARS-CoV-2 infectivity and severity $(10,11)$. Conversely, ACE-2 upregulation may protect the lung via its downstream breakdown of angiotensin II and by increasing the expression of angiotensin-1-7 and 1-9, both of which have vasodilatory and anti-inflammatory effects. This controversy has resulted in the release of statements, from health regulatory authorities and scientific societies, recommending that patients should not discontinue ACEi/ARB therapy in the absence of conclusive evidence of harm(12).

The aim of this study was to examine the role of ACEi/ARB exposure on outcomes among COVID-19 patients with pre-existing hypertension admitted to intensive care units (ICUs). Outcomes included inhospital mortality (primary outcome), length of ICU stay and general ward stay. We used prospectivelycollected data from the international COVID-19 Critical Care Consortium incorporating ExtraCorporeal Membrane Oxygenation for 2019 novel Coronavirus Acute Respiratory Disease (COVID-19CCC/ECMOCARD)(13).

\section{Methods}

\section{Study design and subject participation}

Study data were extracted for analysis from the COVID-19-CCC/ECMOCARD registry, the rationale and design of which have been detailed in Document $\mathbf{S 1}$ (Additional file 1) and previous publication(13). COVID-19-CCC/ECMOCARD is an international observational cohort study involving 354 hospitals spanning 54 countries across six continents. All participating sites obtained local ethics committee approval, and waivers of informed consent were granted for all patients. Recruiting sites and all contributors/collaborators are listed in Document S2 (Additional file 1). The COVID-19-CCC collaborates through the International Severe Acute Respiratory and Emerging Infection Consortium (ISARIC) and their Short PeRiod IncideNce sTudy of Severe Acute Respiratory Infection (SPRINT-SARI). De-identified data were collected prospectively (but not necessarily consecutively) for enrolled patients and stored via the REDCap (Vanderbilt/NIH/NCATS UL1 TRooo445 v.10.0.23) electronic data capture tool hosted at the University of Oxford in the United Kingdom and the University of Queensland in Australia.

Inclusion criteria were: (1) age $\geqq 18$ years, (2) clinically suspected or laboratory confirmed SARS-CoV-2 infection, (3) admission to an ICU, (4) hypertension recorded as a comorbidity at the time of admission, and (5) knowledge of whether they had previously received (taken within 14 days of admission) any antihypertensive therapy. Patients who met all the criteria from (1) to (5) were enrolled. Hypertension were defined as someone having elevated arterial blood pressure diagnosed clinically, $>140 \mathrm{mmHg}$ systolic or $>90 \mathrm{mmHg}$ diastolic.

Patients with pre-existing hypertension (regardless of the blood pressure on admission or during hospital stay) then were divided into two groups; 1) ACEi/ARB group, and 2) non-ACEi/ARB group, based upon 
reported prior use of an ACEi and/or ARB. ACEi/ARB group patients were those with hypertension who had taken ACEi and/or ARB within two weeks of admission to the ICU. Non-ACEi/ARB group patients were those with hypertension who had taken antihypertensive therapy except for ACEi and/or ARB within two weeks of admission.

\section{Data collection and outcome measures:}

For all enrolled patients, the following information was collected using an electronic case report form (Additional file 1: Document S3): demographics, comorbidities, medications, laboratory values, complications, and outcomes. Additional case report forms (Additional file 1: Document S4) were completed for patients who required mechanical ventilation or extracorporeal membrane oxygenation (ECMO). Analyses were performed on all eligible patients included in the database from December 1st, 2019 through December 30th, 2020. Outcomes included in-hospital mortality (primary outcome), length of ICU stay and length of general ward stay assessed up to 90 days following ICU admission.

\section{Statistical analysis}

Baseline characteristics were summarized by descriptive statistics stratified by patient group. Characteristics covered patient demographics, comorbidities, admission signs and symptoms and laboratory results within the first day of ICU admission. Complications during hospitalization, the use of different management strategies in the first 28 days of ICU admission, and final outcomes at the end of the study were also summarized. Continuous variables were reported as medians with interquartile ranges (IQR). Categorial variables were reported as frequencies with percentages. The number of available observations were reported for all variables to show levels of data completeness. Hypothesis testing of between group differences in baseline characteristics was deemed inappropriate following recommendations for statistical reporting of observational studies(14).

Length of stay and in-hospital mortality were analysed as time-to-event outcomes using multi-state survival analysis. Modelling as time-to-event outcomes allowed us to include data on all patients regardless of outcome and accounted for death and discharged alive as competing risks. Outcomes were modelled up to 90 days following admission. Independent right censoring was applied to patients who were still in hospital at 90 days, at their last known follow-up time or at date of transfer to another facility.

Expected length of stay was examined separately for each patient group using a multistate model, unadjusted for baseline characteristics. The model was defined by four states: ICU, General ward, Discharged alive, Died (Additional file 2: Figure S1). Patients entered the model through the general ward state or ICU state if admitted to ICU on the same day as hospital admission. Whilst in ICU, patients either died or returned to the general ward after being discharged from ICU. Following ICU discharge, patients either died or were discharged alive from hospital. Length of stay was estimated from expected times spent in the general ward and ICU states. Cumulative morality risks at 30, 60 and 90 days from ICU admission were estimated from cumulative incidence functions starting in the ICU state, accounting for hospital discharge as a competing risk. 
Follow-up analysis examined the influence of ACEi/ARB use on the hazards of death and discharged alive, accounting for baseline characteristics. Outcomes were analysed using a multi-state Cox proportional hazard model. Baseline characteristics included as model covariates were patient group, age, sex, body mass index (BMI), week of ICU admission, geographic region and major ethnicities (Black, Latin American, South Asian, White/Caucasian, Other including minority groups) and selected comorbidities (diabetes, smoking, chronic cardiac disease, chronic kidney disease). Missing data in covariates (BMI 7\%, Chronic cardiac disease $<1 \%$, Chronic kidney diseases $<1 \%$, Diabetes $<1 \%$ and Smoking 23\%) was assumed missing at random and imputed by multiple imputation using chained equations (MICE). Tests for proportionality based on Schoenfeld residuals were applied to all covariates(14). Model results were reported separately for death and discharged alive as pooled hazard ratios with $95 \%$ confidence intervals $(\mathrm{Cl})$.

We further considered adjusting for the influence of baseline characteristics on reported use of ACEi/ARB versus non-ACEi/ARB treatment(s) before admission. Analysis followed recommendations for inverse probability weighting applied for time-to-event outcomes(15). Inverse probability weights were defined using propensity scores that estimated the probability of belonging to the ACEi/ARB group. Propensity scores considered the same baseline characteristics applied in the Cox proportional hazards model. Resulting propensity scores were then used to weight observations in a multi-state Cox model with patient group as the only covariate.

To evaluate differential effects between ACEi and ARB use, sensitivity analysis considered patient stratification into ACEi, ARB and non-ACEi/ARB groups; associations with the hazards of death and discharge were explored.

All analyses were completed in R 4.0.3. Code for multistate analysis of length of stay was adapted from a published study on COVID-19 patients(16).

\section{Results}

\section{Patient characteristics:}

During the period of study, a total of 1,202 patients with COVID-19 and pre-existing hypertension were admitted to COVID-19-CCC participating ICUs. Of these, 456 patients with missing data of antihypertensive therapy were excluded according to the inclusion criteria. The final cohort for statistical analysis comprised of 746 participants with pre-existing hypertension on antihypertensive therapy

(Additional file 2: Figure S2). The median age of patients was 65 years [IQR, 57 to 73] and 489 were male (66\%). The median Sepsis-related Organ Failure Assessment (SOFA) score and Acute Physiology and Chronic Health Evaluation II (APACHE-II) score was 6 [IQR, 4 to 9] and 18 [IQR, 12 to 24], respectively.

\section{Baseline characteristics:}


A total of 543 patients (73\%) reported use of ACEi/ARB therapy (median age 65 years [IQR, 57-73], 67\% men) within the two weeks prior to ICU admission, while 203 (27\%) had not (median age 66 years [IQR, 55-73], 63\% men). Admission characteristics of the ACEi/ARB and non-ACEi/ARB groups are compared in

Tables 1 and 2. Both groups included similar percentage of diabetes and chronic cardiac disease \{ACEi/ARB group vs. non-ACEi/ARB group: Diabetes, 253 (47\%) vs. 91 (45\%); chronic cardiac disease, 136 $(25 \%)$ vs. 59 (29\%)\}. Chronic kidney disease was reported less in the ACEi/ARB group $\{80(15 \%)$ vs. 53 $(26 \%)\}$. The usage of calcium channel blocker (CCB) and $\beta$-blocker was less frequent in ACEi/ARB groups than non-ACEi/ARB groups $\{114(25 \%)$ vs. $115(57 \%)$, and $112(25 \%)$ vs. $111(55 \%)$, respectively\}.

Details of patient management while in the ICU are summarised in Table 3. Corticosteroids and management of patients in the prone position were more often observed in ACEi/ARB group than nonACEi/ARB group $\{248(56 \%)$ vs. 78 (46\%), and 292 (55\%) of 469 vs. 93 (46\%), respectively\}.

Descriptive statistics for complications recorded at any time during hospitalization are summarised in Table S1 (Additional file 2) and Figure 1. Across selected complications, cardiac arrythmias were more frequent in the ACEi/ARB group \{ACEi/ARB group vs. non-ACEi/ARB group: 154 (33\%) vs. 45 (25\%), $\mathrm{p}=0.055\}$.

Final outcomes at the end of the study are summarised in Table 4. Death in hospital was observed in 260 (48\%) of 543 in ACEi/ARB group and in 112 (55\%) of 203 in non-ACEi/ARB group. Although the main cause of death was similar in the two groups, death due to septic shock was less observed in ACEi/ARB group than non-ACEi/ARB group $\{14(5 \%)$ of 258 vs. 16 (11\%) of 111 , respectively\}.

\section{Length of ICU and hospital stay}

Results for expected ICU and general ward stay are summarised in Figure 2 and Table S2 (Additional file 2). Expected lengths of stay were longer in the ACEi/ARB group than non-ACEi/ARB group, with an average time of 21.4 days $(95 \% \mathrm{Cl}, 19.9$ to 23.0$)$ vs. 16.2 days $(95 \% \mathrm{Cl}, 14.1$ to 18.5$)$ for ICU, and 6.7 days $(95 \% \mathrm{Cl}, 5.9$ to 7.6$)$ vs. 6.3 days $(95 \% \mathrm{Cl}, 5.0$ to 7.7$)$ in general ward, respectively.

\section{In-hospital mortality}

Cumulative incidence of mortality between patient groups indicated differences in mortality up to 30 days from ICU admission (43.5\%, SE $=2.2 \%$ for ACEi/ARB, and 51.3\%, SE $=3.6 \%$ for non-ACEi/ARB). By 90 days, expected mortality estimated from the multistate model was $50.9 \%(\mathrm{SE}=2.2 \%)$ and $59.3 \%$ (SE = 3.5\%) for ACEi/ARB and non-ACEi/ARB groups, respectively (Additional file 2: Table S2). Cumulative probabilities of death and discharged alive from ICU admission between ACEi/ARB and non-ACEi/ARB groups are shown in Figure 3. Hypothesis testing of cumulative incidence functions from time of ICU admission showed a statistically significant difference in the risk of death (test statistic $=7.48, \mathrm{df}=1$, $p=0.006$ ), but not discharged alive (test statistic $=1.18, d f=1, p=0.277$ ).

Results from multistate Cox regression are presented in Figure 4 and Table S3 (Additional file 2). Modelling indicated ACEi/ARB use was associated with a lower hazard of in-hospital mortality (HR, 0.73 , 
$95 \% \mathrm{Cl}, 0.58-0.93, \mathrm{p}=0.011)$, but shared no association with the discharge hazard $(\mathrm{HR}, 0.83,95 \% \mathrm{Cl}, 0.62-$ $1.11, p=0.20$ ). Adjustment by propensity scores showed that ACEi/ARB use was significantly associated with a lower hazard of death ( $\mathrm{HR}, 0.73,95 \% \mathrm{Cl}, 0.58-0.91, \mathrm{p}=0.006)$. (Additional file 2: Table S4).

When ACEi use or ARB use was modelled separately, both ACEi use and ARB returned similar, statistically significant fixed effects for the hazard of death; HR $0.70(95 \% \mathrm{Cl}, 0.53-0.93, \mathrm{p}=0.014)$ and HR $0.74(95 \%$ $\mathrm{Cl}, 0.56-0.97, \mathrm{p}=0.028$ ), for ACEi and ARB respectively (Additional file 2: Table S5). Similar outcomes were observed following adjustment by propensity score (Additional file 2: Table S6), suggesting there was limited evidence of differential effects between ACEi and ARB group on chosen outcomes.

\section{Discussion}

In this large, international, observational study of prospectively recruited patients with COVID-19 and comorbid hypertension requiring admission to an ICU, the previous use of ACEi/ARB prior to ICU admission was common. In this cohort, we made two important clinical observations. First, the previous use of ACEi/ARB was associated with a reduced risk of in-hospital mortality, compared with not being on either drug class, with the greatest separation between these two groups evident within the first 30 days after admission. Second, despite the improved in-hospital mortality, patients with ACEi/ARB showed longer length of ICU and general ward stay.

Previous use of $A C E \mathrm{~A} / \mathrm{ARB}$ was associated with a reduced risk of in-hospital mortality, compared with not being on either drug class. This is a study to examine mortality of ACEi/ARB vs. non-ACEi/ARB users among critically ill COVID-19 patients specifically managed in the ICU settings. Compared with previous research, our analysis accounted for potential confounders as baseline characteristics, including cardiac comorbidities. In a previous study of a cohort of 187 patients with COVID-19, Guo et al reported that the mortality of RAAS inhibitor users $(36.8 \% ; 6$ of 19$)$ was higher than that of non-users of RAAS inhibitors $(25.6 \% ; 43 \text { of } 168)^{10}$. However, it was uncertain if the higher mortality was related to RAAS inhibitors or a different background, where the RAAS inhibitor group might have a higher rate of comorbidities of cardiovascular disease. A recent meta-analysis involving 28,872 of COVID-19 patients, which showed a significant association between RAAS inhibition and reduced risk of death in the sub-cohort of hypertension(17), provides similar evidence to that reported in our results. Although cardiac arrhythmias were more common in the ACEi/ARB group in a current study corresponding with previous reports $(18,19)$, it did not impact rates of mortality. Furthermore, the frequency of other cardiac complications during admission (e.g. heart failure, cardiac ischemia and cardiac arrest) was similar between the two groups. As such, the benefit of RAAS inhibitors could be distinct from the well-established prognostic benefit that ACEi/ARB therapy has on cardiovascular diseases(20). This is potentially related to the anti-inflammatory actions of angiotensin-1-7 and 1-9, both of which are increased by ACEi/ARB through upregulation of ACE-2 $(21,22)$. Both have vasodilatory and anti-inflammatory effects through Mas receptors and angiotensin II type 2 receptors, respectively $(21,23)$. Some researchers, like Gurwitz et al, even proposed RAAS inhibitors as a tentative treatment for COVID-19 aiming to increase ACE-2(24) expecting antiinflammatory effects. In addition, the lower rate of death due to septic shock in ACEi/ARB group in our 
study, corresponding with another study(9), may be due to the anti-inflammatory effect of ACEi/ARB. In 2020, Hsu et al conducted a retrospective, propensity score-matched study targeting 3,168 sepsis patients with prior use of RAAS inhibitors, but unrelated to COVID-19 infection. They reported that the short-term (up to 90 days) mortality after sepsis was substantially lower among those who were already established on RAAS inhibitor treatment when sepsis occurred(25). Evidence is limited, but some experimental studies suggested that angiotensin II has a pro-inflammatory effect and causes endothelial and microvascular dysfunctions $(26,27)$. RAAS inhibitors may also reduce inflammatory cytokines thus preventing sepsis-related adverse effects by reducing angiotensin II through ACE-2 upregulation.

Despite the improved in-hospital mortality, patients with ACEi/ARB showed a longer length of ICU and general ward stay. In the retrospective study, targeting from non-severe to severe hospitalized COVID-19 patients, Li et al reported that ACEi/ARB group $(n=115)$ and non-ACEi/ARB group $(n=247)$ did not have a significant difference in hospital stay \{median 19 days [IQR 13-27] and median 19 days [IQR 11-27], respectively\} in contrast to this study. However, when they compared the length of hospital stay of COVID19 patients with hypertension $(n=362)$ between survivors $(n=285)$ and non-survivors $(n=77)$, the data showed that survivors had a trend to stay longer \{median 19 days [IQR 13-26]\} than non-survivors \{median 15 days [IQR 6-30], $\mathrm{p}=0.73$ \}(28). This may potentially be because the non-survivors could have had more severe disease and died earlier than the survivors. This interpretation is similar to that by Rees et al in a systematic review showing that patients who were discharged alive tended to stay longer than those who died during admission(29).

This is an international report investigating any association between ACEi/ARB use and outcomes in a large group of critically ill COVID-19 patients specifically managed in the ICU settings. The inferences are, therefore, not limited by clinical practices specific to single-country studies. Except for differences such as the rates of corticosteroid administration and prone positioning, the two treatment groups were well matched, in terms of baseline characteristics and the clinical management they received.

Some of the limitations exist in this study. First, our data lacks the information on the latest timing of medications taken in the two weeks prior to admission and whether they were continued posthospitalization. Similarly, we lack data on dose and specific ACEi/ARB agents. Therefore, our results are based on the estimation that the enough effect of medications with an appropriate dosage continued at least up to hospitalization. Second, limited data availability on SOFA score and APACHE-II score meant that adjustment for disease severity at time of ICU admission was not possible. However, considering that over $95 \%$ of patients in both ACEi/ARB group and non-ACEi/ARB group required mechanical ventilation, it is certain that patients enrolled were critically ill patients requiring ICU management. Finally, the voluntary nature of site participation means that our data could be skewed favouring centres with sufficient resources to enter data.

\section{Abbreviations}

ACE-2: Angiotensin-converting enzyme 2 
ACEi: Angiotensin-converting enzyme inhibitor

APACHE-II: Acute Physiology and Chronic Health Evaluation II

ARB: Angiotensin receptor blockers

ARDS: Acute respiratory distress syndrome

BMI: Body mass index

CCB: Calcium channel blocker

CCC: Critical care consortium

Cl: Confidence interval

COVID-19: Coronavirus disease-19

ECMO: Extracorporeal membrane oxygenation

ECMOCARD: ExtraCorporeal Membrane Oxygenation for 2019 novel Coronavirus Acute

Respiratory Disease

HR: Hazard ratio

ICU: Intensive care unit

IQR: Interquartile ranges

ISARIC: the International Severe Acute Respiratory and Emerging Infection Consortium

MICE: Multiple imputation using chained equations

RAAS: Renin-angiotensin-aldosterone system

SARS-CoV-2: Severe acute respiratory syndrome coronavirus 2

SE: Standard error

SOFA: Sepsis-related Organ Failure Assessment

SPRINT-SARI: Short PeRiod IncideNce sTudy of Severe Acute Respiratory Infection

\section{Declarations}

Ethics approval and consent to participate 
This Study was conducted as a cardiac sub-study of the COVID-19-CCC/ECMOCARD registry(13). As this study was a multicentre international study, each participating site obtained local ethics committee approval, and waivers of informed consent were granted for all patients as all data are collected routinely. A complete summary of ethics and regulatory approvals is included in the main COVID-19-CCC protocol(13). De-identified data were collected for enrolled patients.

\section{Consent for publication}

Not applicable

\section{Availability of data and materials}

The data that support the findings of this study are available from the COVID-19-CCC/ECMOCARD research group but restrictions apply to the availability of these data, which were used under license for the current study, and so are not publicly available. Data are however available from the authors upon reasonable request and with permission of the COVID-19-CCC/ECMOCARD research group.

\section{Competing interests}

GLB and JFF received research funds, through their affiliated institution, from Fisher \& Paykel for studies related to high-flow oxygen therapy. The remaining authors have nothing to disclose.

\section{Funding}

This study received discretionary funding from University of Queensland, Wesley Medical Research, The Prince Charles Hospital Foundation, The Health Research Board of Ireland, Biomedicine international training research programme for excellent clinician-scientists, European Union's research and innovation programme (Horizon 2020), and la Caixa Foundation. All of them have not and will not have any input into study design, data collection, data analysis or interpretation, or manuscript preparation.

\section{Authors' contributions}

KS, NW, NO, JYS, GLB, JFF and RCA were responsible for the study concept and design. KS, NW, JPF, JYS, GLB and JFF were responsible for the acquisition and analysis of data. All authors contributed to the interpretation of the data. $\mathrm{KS}, \mathrm{NH}, \mathrm{NO}$ and JPF drafted the manuscript. All authors critically revised the manuscript for important intellectual content and approved the final version. RCA is a guarantor. The corresponding author attests that all listed authors meet authorship criteria.

\section{Acknowledgements}

We appreciate all collaborative organizations including ISARIC/SPRINT-SARI and all investigators (Additional file 1: Document S2) who registered patients' data on behalf of the COVID-19 Critical Care Consortium. 


\section{References}

1. Guan W, Ni Z, Hu Y, Liang W, Ou C, He J, et al. Clinical Characteristics of Coronavirus Disease 2019 in China. N Engl J Med. 2020;382(18):1708-20.

2. Fang L, Karakiulakis $G$, Roth $M$. Are patients with hypertension and diabetes mellitus at increased risk for COVID-19 infection? Vol. 8, The Lancet Respiratory Medicine. 2020. p. e21.

3. Esler M, Esler D. Can angiotensin receptor-blocking drugs perhaps be harmful in the COVID-19 pandemic? Vol. 38, Journal of Hypertension. 2020. p. 781-2.

4. Hoffmann M, Kleine-Weber H, Schroeder S, Krüger N, Herrler T, Erichsen S, et al. SARS-CoV-2 Cell Entry Depends on ACE2 and TMPRSS2 and Is Blocked by a Clinically Proven Protease Inhibitor. Cell. 2020;181(2):271-280.e8.

5. Zhou P, Yang X Lou, Wang XG, Hu B, Zhang L, Zhang W, et al. A pneumonia outbreak associated with a new coronavirus of probable bat origin. Nature. 2020 Mar 12;579(7798):270-3.

6. Walls AC, Park YJ, Tortorici MA, Wall A, McGuire AT, Veesler D. Structure, Function, and Antigenicity of the SARS-CoV-2 Spike Glycoprotein. Cell. 2020 Apr 16;181(2):281-292.e6.

7. Soler MJ, Barrios C, Oliva R, Batlle D. Pharmacologic modulation of ACE2 expression. Curr Hypertens Rep. 2008;10(5):410-4.

8. Jarcho JA, Ingelfinger JR, Hamel MB, D’Agostino RB, Harrington DP. Inhibitors of the ReninAngiotensin-Aldosterone System and Covid-19. N Engl J Med. 2020;382(25):2462-4.

9. Zhang P, Zhu L, Cai J, Lei F, Qin JJ, Xie J, et al. Association of Inpatient Use of AngiotensinConverting Enzyme Inhibitors and Angiotensin II Receptor Blockers with Mortality among Patients with Hypertension Hospitalized with COVID-19. Circ Res. 2020;126(12):1671-81.

10. Guo T, Fan Y, Chen M, Wu X, Zhang L, He T, et al. Cardiovascular Implications of Fatal Outcomes of Patients With Coronavirus Disease 2019 (COVID-19). JAMA Cardiol. 2020;5(7):811-8.

11. Singh AK, Gupta R, Misra A. Comorbidities in COVID-19: Outcomes in hypertensive cohort and controversies with renin angiotensin system blockers. Diabetes Metab Syndr Clin Res Rev. 2020 Jul 1;14(4):283-7.

12. Bozkurt B, Kovacs R, Harrington B. Joint HFSA/ACC/AHA Statement Addresses Concerns Re: Using RAAS Antagonists in COVID-19. Vol. 26, Journal of Cardiac Failure. Churchill Livingstone Inc.; 2020. p. 370.

13. Li Bassi G, Suen J, Barnett AG, Corley A, Millar J, Fanning J, et al. Design and rationale of the COVID19 Critical Care Consortium international, multicentre, observational study. BMJ Open. 2020 Dec 2;10(12).

14. von Elm E, Altman DG, Egger M, Pocock SJ, Gøtzsche PC, Vandenbroucke JP. The Strengthening the Reporting of Observational Studies in Epidemiology (STROBE) statement: guidelines for reporting observational studies. Lancet. 2007;370(9596):1453-7.

15. Austin PC. Variance estimation when using inverse probability of treatment weighting (IPTW) with survival analysis. Stat Med. 2016;35(30):5642-55. 
16. Hazard D, Kaier K, Von Cube M, Grodd M, Bugiera L, Lambert J, et al. Joint analysis of duration of ventilation, length of intensive care, and mortality of COVID-19 patients: A multistate approach. BMC Med Res Methodol. 2020 Aug 11;20(1).

17. Baral R, White M, Vassiliou VS. Effect of Renin-Angiotensin-Aldosterone System Inhibitors in Patients with COVID-19: a Systematic Review and Meta-analysis of 28,872 Patients. Vol. 22, Current Atherosclerosis Reports. Springer; 2020. p. 1-9.

18. Cure $E$, Cumhur Cure M. Angiotensin-converting enzyme inhibitors and angiotensin receptor blockers may be harmful in patients with diabetes during COVID-19 pandemic. Diabetes Metab Syndr Clin Res Rev. 2020;14(4):349-50.

19. Aleksova A, Ferro F, Gagno G, Cappelletto C, Santon D, Rossi M, et al. COVID-19 and renin-angiotensin system inhibition: role of angiotensin converting enzyme 2 (ACE2) - Is there any scientific evidence for controversy? Vol. 288, Journal of Internal Medicine. Blackwell Publishing Ltd; 2020. p. 410-21.

20. Shah R, Wang Y, Foody JAM. Effect of Statins, Angiotensin-Converting Enzyme Inhibitors, and Beta Blockers on Survival in Patients $\geq 65$ Years of Age With Heart Failure and Preserved Left Ventricular Systolic Function. Am J Cardiol. 2008;101(2):217-22.

21. McKinney CA, Fattah C, Loughrey CM, Milligan G, Nicklin SA. Angiotensin-(1-7) and angiotensin-(1-9): Function in cardiac and vascular remodelling. Vol. 126, Clinical Science. 2014. p. 815-27.

22. Chen J, Jiang Q, Xia X, Liu K, Yu Z, Tao W, et al. Individual variation of the SARS-CoV-2 receptor ACE2 gene expression and regulation. Aging Cell. $2020 \mathrm{Jul}$ 1;19(7):1-12.

23. De Wit E, Van Doremalen N, Falzarano D, Munster VJ. SARS and MERS: Recent insights into emerging coronaviruses. Vol. 14, Nature Reviews Microbiology. 2016. p. 523-34.

24. Gurwitz D. Angiotensin receptor blockers as tentative SARS-CoV-2 therapeutics. Drug Dev Res. 2020 Aug 4;81(5):537-40.

25. Hsu WT, Galm BP, Schrank G, Hsu TC, Lee SH, Park JY, et al. Effect of Renin-Angiotensin-Aldosterone System Inhibitors on Short-Term Mortality after Sepsis: A Population-Based Cohort Study. Hypertension. 2020;75(2):483-91.

26. Corrêa TD, Jeger V, Pereira AJ, Takala J, Djafarzadeh S, Jakob SM. Angiotensin II in septic shock: Effects on tissue perfusion, organ function, and mitochondrial respiration in a porcine model of fecal peritonitis. Crit Care Med. 2014;42(8).

27. Hagiwara S, Iwasaka H, Matumoto S, Hidaka S, Noguchi T. Effects of an angiotensin-converting enzyme inhibitor on the inflammatory response in in vivo and in vitro models. Crit Care Med. 2009;37(2):626-33.

28. Li J, Wang X, Chen J, Zhang H, Deng A. Association of Renin-Angiotensin System Inhibitors with Severity or Risk of Death in Patients with Hypertension Hospitalized for Coronavirus Disease 2019 (COVID-19) Infection in Wuhan, China. JAMA Cardiol. 2020 Jul 1;5(7):825-30.

29. Rees EM, Nightingale ES, Jafari Y, Waterlow NR, Clifford S, B Pearson CA, et al. COVID-19 length of hospital stay: a systematic review and data synthesis. BMC Med. 2020;18:270. 


\section{Tables}

Table 1. Baseline characteristics 


\begin{tabular}{|c|c|c|c|c|}
\hline Characteristic & ACEi/ARB & $\begin{array}{l}\text { Available } \\
\text { number }\end{array}$ & non-ACEi/ARB & $\begin{array}{l}\text { Available } \\
\text { number }\end{array}$ \\
\hline \multicolumn{5}{|c|}{ Demographics } \\
\hline Age (years), median (IQR) & $65(57$ to 73$)$ & 543 & $66(55$ to 73$)$ & 203 \\
\hline Male, n (\%) & $362(67)$ & 543 & $127(63)$ & 203 \\
\hline BMI (kg/m2), median (IQR) & $\begin{array}{l}29.4(26.1 \text { to } \\
34.0)\end{array}$ & 494 & $\begin{array}{l}29.2(24.8 \text { to } \\
33.9)\end{array}$ & 194 \\
\hline \multicolumn{5}{|l|}{ Ethnicity, n (\%) } \\
\hline Aboriginal & $7(1)$ & 506 & $1(1)$ & 195 \\
\hline Arab & $11(2)$ & 506 & $4(2)$ & 195 \\
\hline Black & $58(11)$ & 506 & $48(25)$ & 195 \\
\hline East Asian & $21(4)$ & 506 & $10(5)$ & 195 \\
\hline South Asian & $21(4)$ & 506 & $13(7)$ & 195 \\
\hline West Asian & $3(1)$ & 506 & $1(1)$ & 195 \\
\hline Latin American & $102(20)$ & 506 & $17(9)$ & 195 \\
\hline Other & $28(6)$ & 506 & $17(9)$ & 195 \\
\hline White & $255(50)$ & 506 & $84(43)$ & 195 \\
\hline \multicolumn{5}{|l|}{ Geographic region, n (\%) } \\
\hline Africa & $55(10)$ & 543 & $39(19)$ & 203 \\
\hline Asia & $6(1)$ & 543 & $1(0)$ & 203 \\
\hline Australia and New Zealand & $165(30)$ & 543 & $57(28)$ & 203 \\
\hline Europe & $102(19)$ & 543 & $8(4)$ & 203 \\
\hline Latin America and the Caribbean & $196(36)$ & 543 & $98(48)$ & 203 \\
\hline \multirow[t]{2}{*}{ Northern America } & $55(10)$ & 543 & $39(19)$ & 203 \\
\hline & \multicolumn{4}{|c|}{ Admission signs and symptoms } \\
\hline $\begin{array}{l}\text { Heart rate (beats/minute), } \\
\text { median (IQR) }\end{array}$ & $92(80$ to 105$)$ & 515 & $92(78$ to 106$)$ & 186 \\
\hline $\begin{array}{l}\text { Systolic BP (mmHg), } \\
\text { median (IQR) }\end{array}$ & $\begin{array}{l}130(114 \text { to } \\
148)\end{array}$ & 513 & $\begin{array}{l}128(110 \text { to } \\
150)\end{array}$ & 188 \\
\hline Diastolic BP (mmHg), & 72 (61 to 82$)$ & 513 & $70(61$ to 83$)$ & 188 \\
\hline
\end{tabular}




\begin{tabular}{|c|c|c|c|c|}
\hline $\begin{array}{l}\text { Respiratory rate (breaths/minute), } \\
\text { median (IQR) }\end{array}$ & $25(20$ to 30$)$ & 490 & $24(20$ to 30$)$ & 181 \\
\hline Oxygen saturation (\%), & $91(84$ to 95$)$ & 516 & $94(89$ to 97$)$ & 191 \\
\hline \multicolumn{5}{|l|}{ median (IQR) } \\
\hline Cough, n (\%) & $379(75)$ & 507 & $129(70)$ & 184 \\
\hline Fever, n (\%) & $412(80)$ & 518 & $142(75)$ & 190 \\
\hline Malaise, n (\%) & $277(58)$ & 481 & $79(44)$ & 178 \\
\hline \multirow[t]{2}{*}{ Dyspnoea, n (\%) } & $437(82)$ & 530 & $159(82)$ & 530 \\
\hline & \multicolumn{4}{|c|}{ Reported comorbidities } \\
\hline Smoking, n (\%) & $167(40)$ & 416 & $69(45)$ & 153 \\
\hline Diabetes, n (\%) & $253(47)$ & 539 & $91(45)$ & 201 \\
\hline Chronic cardiac disease, $\mathrm{n}(\%)$ & $136(25)$ & 539 & $59(29)$ & 202 \\
\hline Chronic pulmonary disease, $\mathrm{n}(\%)$ & $72(13)$ & 541 & $43(21)$ & 201 \\
\hline Chronic kidney disease, n (\%) & $80(15)$ & 540 & $53(26)$ & 201 \\
\hline Chronic neurological disorder, $\mathrm{n}(\%)$ & $36(7)$ & 539 & $18(9)$ & 201 \\
\hline Severe liver disease, $\mathrm{n}(\%)$ & $27(5)$ & 541 & $21(10)$ & 202 \\
\hline \multirow[t]{2}{*}{ Malignant neoplasm, n (\%) } & $32(6)$ & 540 & $13(6)$ & 201 \\
\hline & \multicolumn{4}{|c|}{$\begin{array}{l}\text { Reported use of anti-hypertensive drugs on } \\
\text { admission }\end{array}$} \\
\hline Diuretic, n (\%) & $94(20)$ & 462 & $46(23)$ & 203 \\
\hline Calcium channel blocker, n (\%) & $114(25)$ & 462 & $115(57)$ & 203 \\
\hline ß-blocker, n (\%) & $112(24)$ & 462 & $111(55)$ & 203 \\
\hline a-blocker, n (\%) & $6(1)$ & 462 & $4(2)$ & 203 \\
\hline
\end{tabular}

ACEi: angiotensin-converting enzyme inhibitor, ARB: angiotensin II receptor blocker, BMI: body mass index

Table 2. Laboratory examinations within first $24 \mathrm{hrs}$ of ICU admission. 


\begin{tabular}{|lllll|}
\hline Characteristic & $\begin{array}{l}\text { ACEi/ARB } \\
\text { median (IQR) }\end{array}$ & $\begin{array}{l}\text { Available } \\
\text { number }\end{array}$ & $\begin{array}{l}\text { non-ACEi/ARB } \\
\text { median (IQR) }\end{array}$ & $\begin{array}{l}\text { Available } \\
\text { number }\end{array}$ \\
\hline Haemoglobin $(\mathrm{g} / \mathrm{L})$ & $12.7(11.0$ to 13.8$)$ & 417 & $11.4(9.6$ to 13.5$)$ & 169 \\
\hline Neutrophil $\left(10^{9} / \mathrm{L}\right)$ & $8.6(5.7$ to 11.9$)$ & 310 & $7.2(4.2$ to 11.0$)$ & 102 \\
\hline Lymphocyte $\left(10^{9} / \mathrm{L}\right)$ & $0.8(0.5$ to 1.2$)$ & 322 & $0.7(0.4$ to 1.1$)$ & 113 \\
\hline Platelets $\left(10^{9} / \mathrm{L}\right)$ & $220(167$ to 280$)$ & 398 & $196(136$ to 270$)$ & 166 \\
\hline C-reactive $p r o t e i n ~(m g / L)$ & $130(48$ to 257$)$ & 126 & $121(37$ to 249$)$ & 60 \\
\hline Procalcitonin $(\mathrm{ng} / \mathrm{mL})$ & $0.30(0.17$ to 0.94$)$ & 141 & $0.75(0.26$ to 1.80$)$ & 52 \\
\hline Bilirubin $(\mu \mathrm{mol} / \mathrm{L})$ & $0.58(0.35$ to 0.90$)$ & 305 & $0.60(0.40$ to 1.00$)$ & 125 \\
\hline AST $(\mathrm{U} / \mathrm{L})$ & $0.80(0.57$ to 1.25$)$ & 256 & $0.80(0.55$ to 1.17$)$ & 109 \\
\hline ALT $(\mathrm{U} / \mathrm{L})$ & $0.60(0.38$ to 1.14$)$ & 259 & $0.52(0.33$ to 0.87$)$ & 113 \\
\hline Blood urea nitrogen $(\mathrm{mmol} / \mathrm{L})$ & $2.1(1.2$ to 3.6$)$ & 362 & $2.1(1.2$ to 4.0$)$ & 156 \\
\hline Creatinine $(\mu \mathrm{mol} / \mathrm{L})$ & $1.1(0.8$ to 1.6$)$ & 415 & $1.2(0.9$ to 2.2$)$ & 169 \\
\hline Sodium $(\mathrm{mmol} / \mathrm{L})$ & $137(134$ to 140$)$ & 333 & $138(135$ to 142$)$ & 134 \\
\hline Potassium $(\mathrm{mmol} / \mathrm{L})$ & $4.1(3.7$ to 4.6$)$ & 334 & $4.2(3.7$ to 4.6$)$ & 133 \\
\hline
\end{tabular}

ACEi: angiotensin-converting enzyme inhibitor, ALT: alanine aminotransferase, ARB: angiotensin II receptor blocker, AST: aspartate aminotransferase

Table 3. ICU management within the first 28 days following ICU admission. 


\begin{tabular}{|lllll|}
\hline Characteristic & ACEi/ARB & Available & non-ACEi/ARB & Available \\
& $\mathbf{n}(\%)$ & number & $\mathbf{n}(\%)$ & number \\
\hline Antivirals & $225(53)$ & 427 & $92(57)$ & 162 \\
\hline Antibiotics & $506(96)$ & 527 & $189(94)$ & 200 \\
\hline Corticosteroids & $248(56)$ & 440 & $78(46)$ & 170 \\
\hline Heparin & $356(87)$ & 411 & $128(84)$ & 152 \\
\hline Prone position & $292(55)$ & 532 & $93(46)$ & 202 \\
\hline Mechanical ventilation & $511(96)$ & 533 & $193(96)$ & 202 \\
\hline ECMO & $81(15)$ & 532 & $26(13)$ & 202 \\
\hline Inhaled nitric oxide & $56(11)$ & 532 & $23(11)$ & 202 \\
\hline CRRT & $91(18)$ & 499 & $39(21)$ & 188 \\
\hline Vasoactive drugs & $308(63)$ & 492 & $117(63)$ & 187 \\
\hline Cardiac assist devices & $34(7)$ & 501 & $12(6)$ & 192 \\
\hline Transfused RBC & $112(24)$ & 461 & $48(26)$ & 183 \\
\hline Transfused Platelets & $18(4)$ & 461 & $5(3)$ & 183 \\
\hline Transfused Plasma & $23(5)$ & 461 & $11(6)$ & 183 \\
\hline
\end{tabular}

ACEi: angiotensin-converting enzyme inhibitor, ARB: angiotensin II receptor blocker, CRRT: continuous renal replacement therapies, ECMO: extracorporeal membrane oxygenation

Table 4. Final outcomes at the end of study. 


\begin{tabular}{|lllll|}
\hline Outcome & $\begin{array}{l}\text { ACEi/ARB } \\
\mathbf{n}(\%)\end{array}$ & $\begin{array}{l}\text { Available } \\
\text { number }\end{array}$ & $\begin{array}{l}\text { non-ACEi/ARB } \\
\mathbf{n}(\%)\end{array}$ & $\begin{array}{l}\text { Available } \\
\text { number }\end{array}$ \\
\hline Died in hospital & $260(48)$ & 543 & $112(55)$ & 203 \\
\hline Discharged alive from hospital & $227(42)$ & 543 & $69(34)$ & 203 \\
\hline Transferred to another facility & $7543(1)$ & 543 & $1(0)$ & 203 \\
\hline Outcome not finalised & $49(9)$ & 543 & $21(10)$ & 203 \\
\hline Recorded cause of death & & & & 111 \\
\hline Cardiac Failure & $17(7)$ & 258 & $4(4)$ & 111 \\
\hline Cerebrovascular accident & $3(1)$ & 258 & $3(3)$ & 111 \\
\hline Haemorrhagic shock & $3(1)$ & 258 & $0(0)$ & 111 \\
\hline Multi-organ failure & $86(33)$ & 258 & $30(27)$ & 111 \\
\hline Respiratory failure & $100(39)$ & 258 & $48(43)$ & 111 \\
\hline Septic shock & $14(5)$ & 258 & $16(14)$ & 111 \\
\hline Other & $19(7)$ & 258 & $7(6)$ & 111 \\
\hline Missing & $16(6)$ & 258 & $3(3)$ & \\
\hline
\end{tabular}

Cause of death information is provided for patients known to have died in hospital. ACEi: angiotensinconverting enzyme inhibitor, ARB: angiotensin II receptor blocker

\section{Figures}




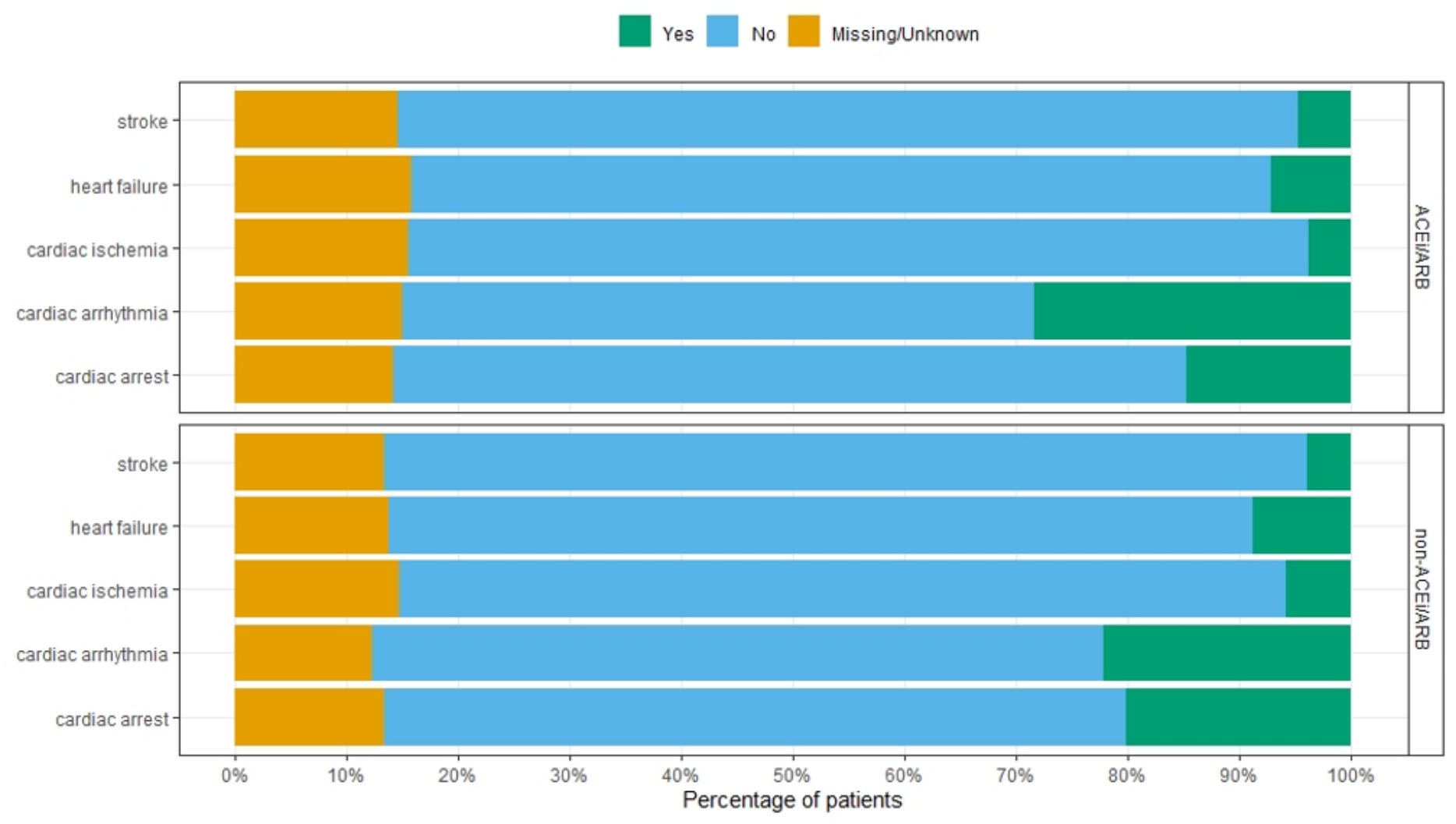

\section{Figure 1}

Descriptive statistics for complications recorded at any time during hospitalization, by patient group. ACEi: angiotensin-converting enzyme inhibitor, ARB: angiotensin II receptor blocker 
A)

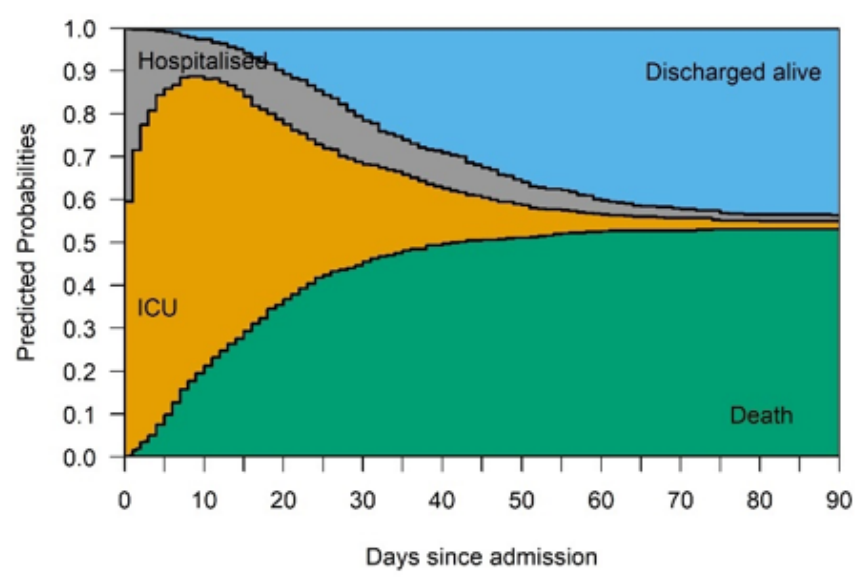

B)

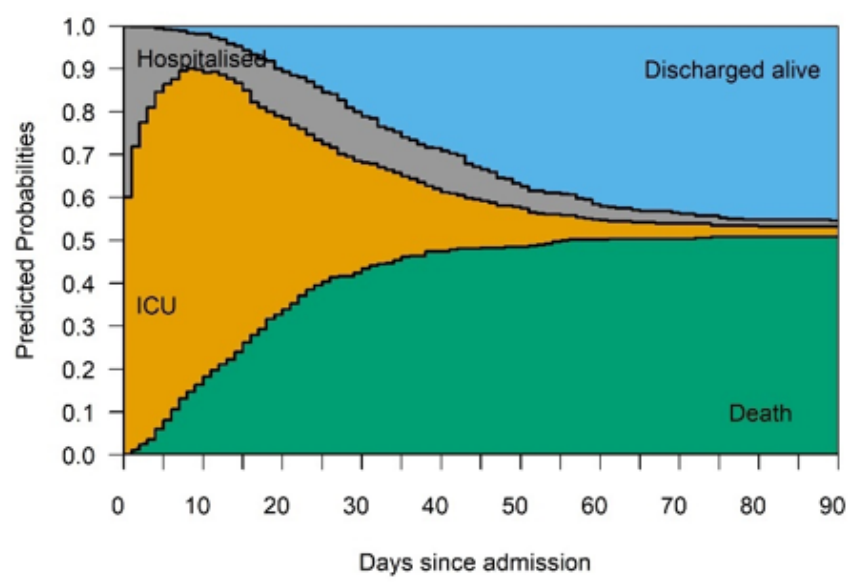

C)

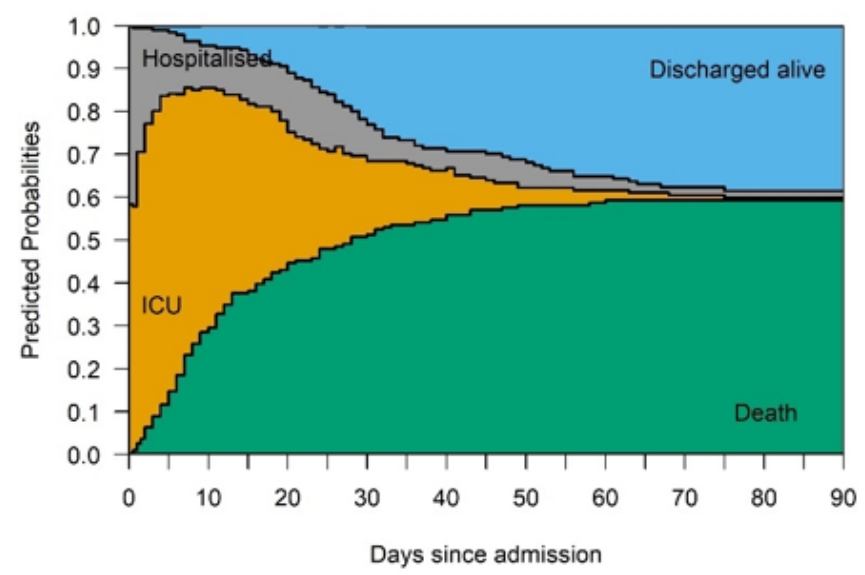

Figure 2

Multistate model results for expected ICU stay and hospital stay up to 90 days from hospital admission. (A) all included patients ( $n=663)$; (B) ACEi/ARB group; and (C) Non-ACEi/ARB group. ACEi: angiotensinconverting enzyme inhibitor, ARB: angiotensin II receptor blocker, $\mathrm{Cl}$ : confidence intervals, ICU: intensive care unit 


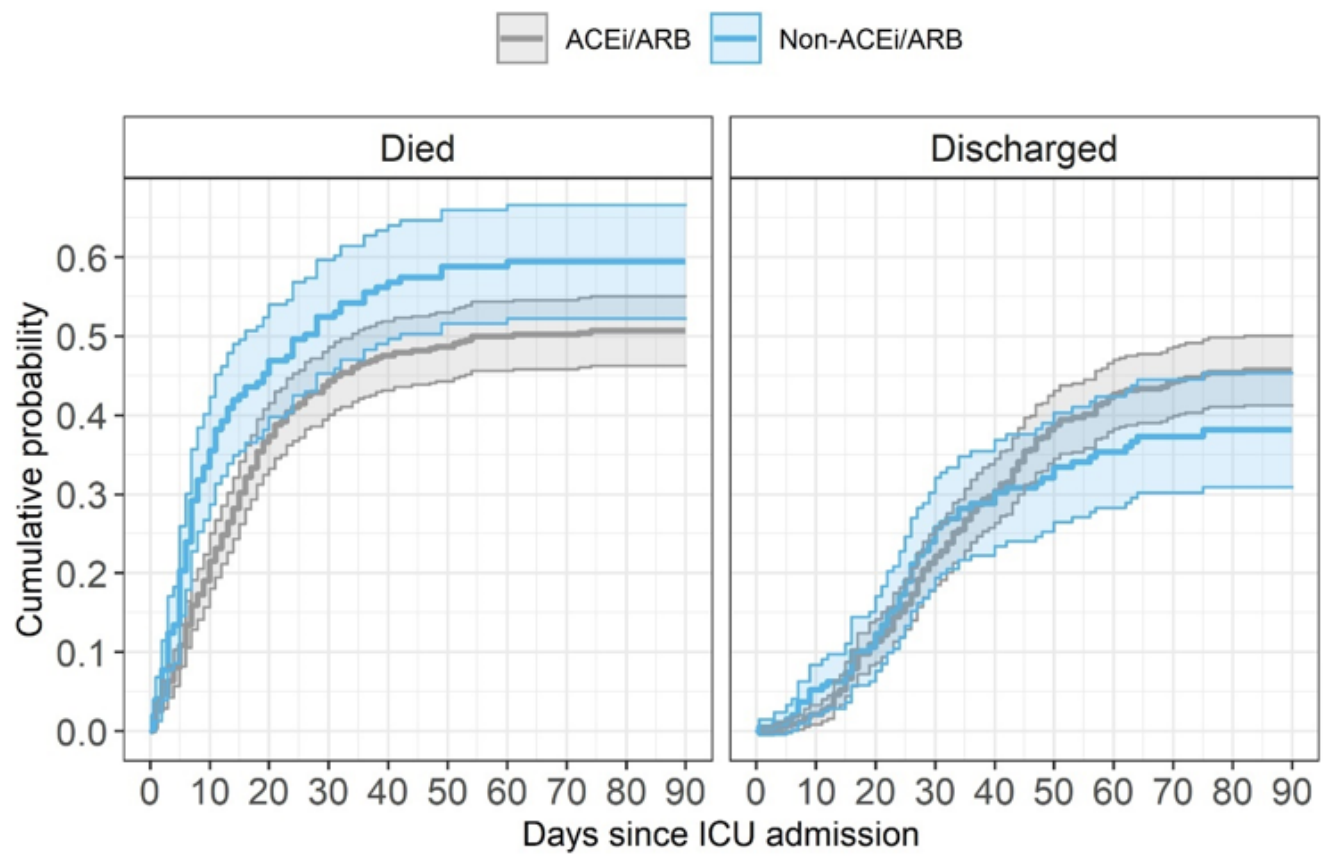

B)

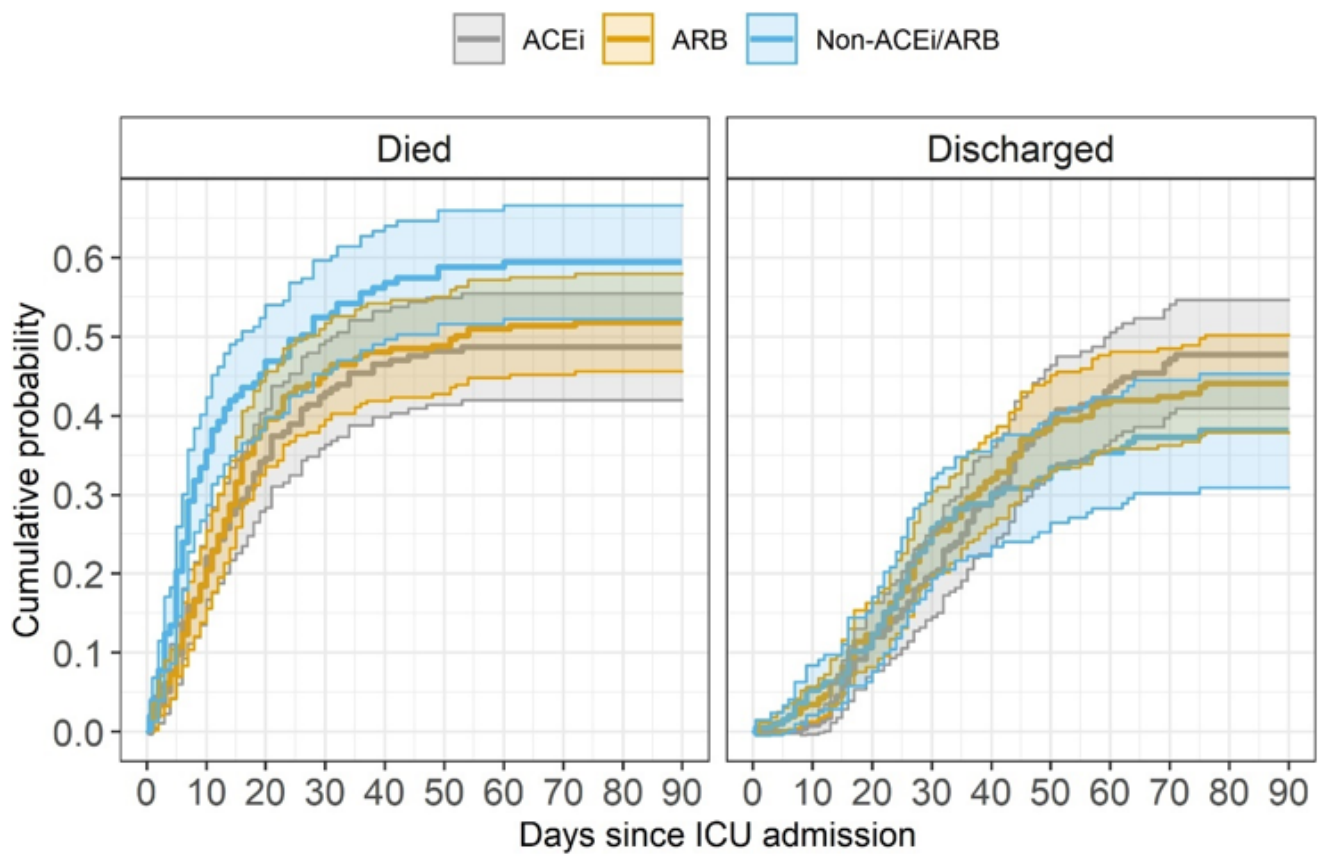

Figure 3

Cumulative probabilities of death and discharge from ICU admission. A) between ACEi/ARB and nonACEi/ARB groups; B) between ACEI, ARB and non-ACEI/ARB groups. Results are not adjusted for baseline characteristics. ACEi: angiotensin-converting enzyme inhibitor, ARB: angiotensin II receptor blocker, ICU: intensive care unit 
A)

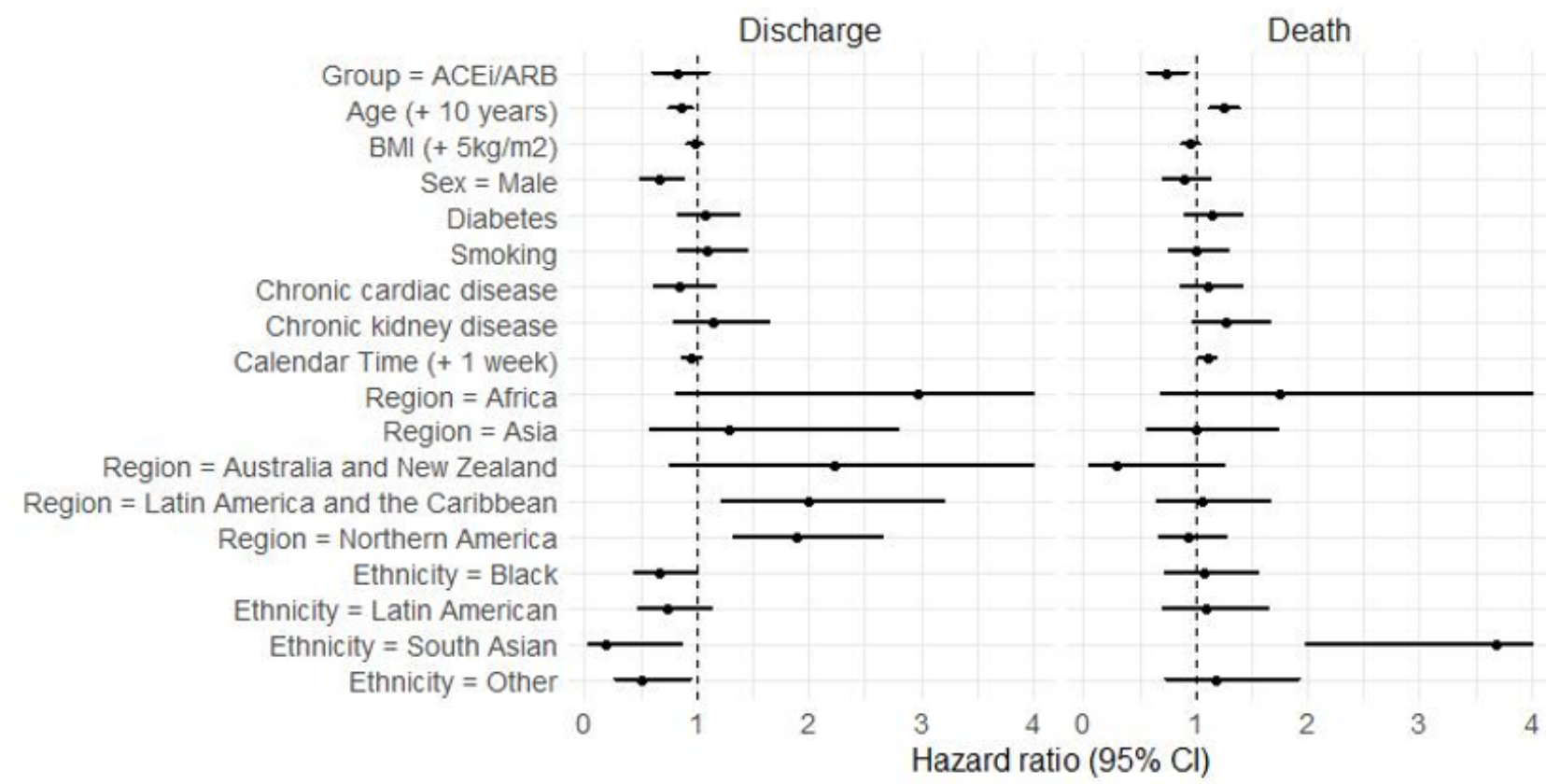

B)

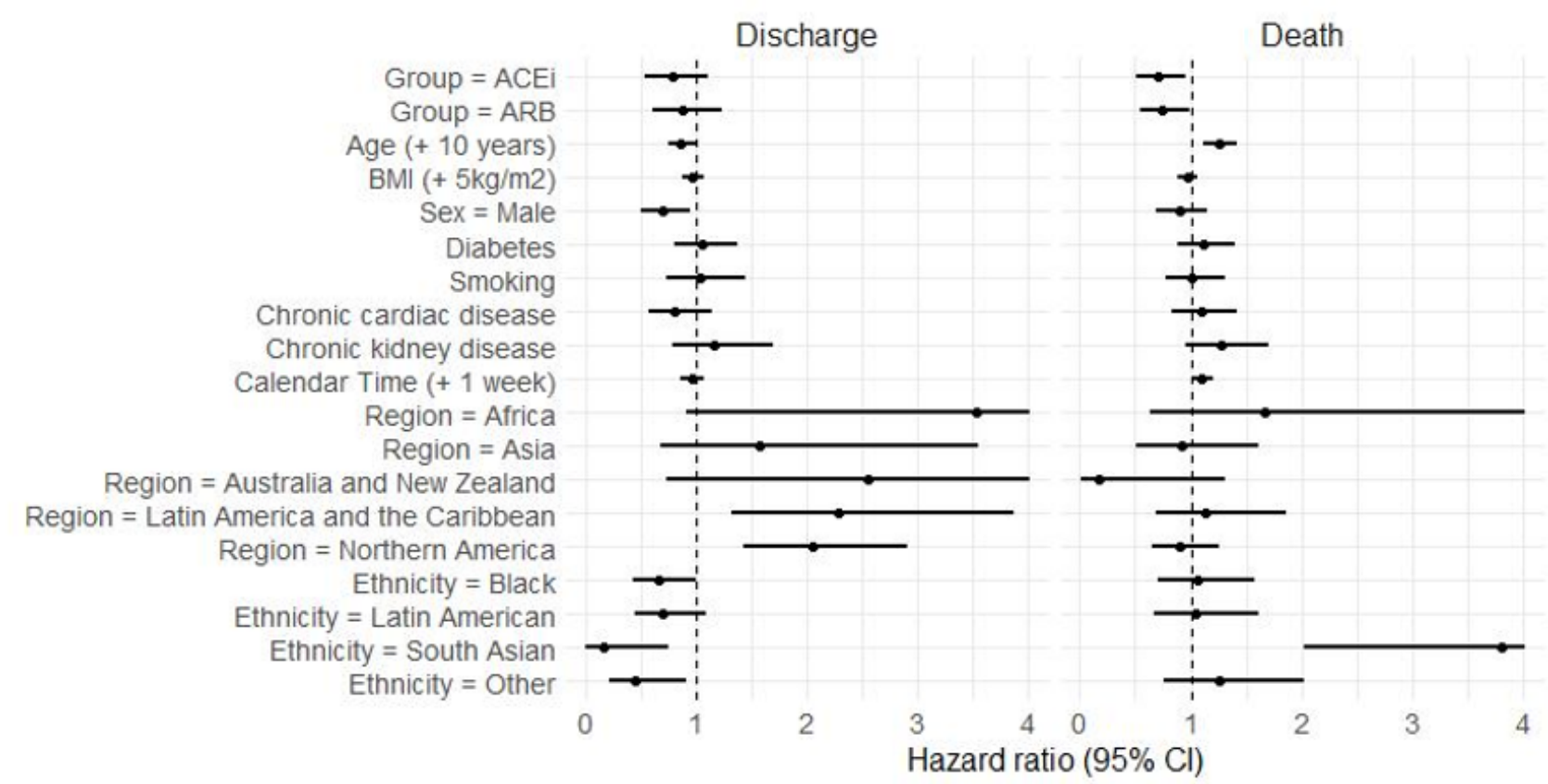

Figure 4

Forest plot derived from multistate Cox regression. A) Primary analysis with ACEi/ARB versus nonACEi/ARB groups as a fixed effect; B) Sensitivity analysis where ACEi/ARB is split into ACEi and ARB groups ( $n=41$ excluded due to insufficient data to determine stratification). This accounts for competing risks of in-hospital death and hospital discharge up to 90 days from ICU admission. Week of ICU admission indicates calendar time. ACEi: angiotensin-converting enzyme inhibitor, ARB: angiotensin II 
receptor blocker, BMI: body mass index, Cl: confidence intervals, ICU: intensive care unit. Terms with an upper confidence limit greater than 4 have been truncated for presentation.

\section{Supplementary Files}

This is a list of supplementary files associated with this preprint. Click to download.

- Additionalfile1DocumentS1S4.pdf

- Additionalfile2FigureS1S2andTablesS1S6BMCCardiovascularDisordersfinalclean.docx 